\title{
Performance Analysis of WDM-RoF System with CO- OFDM for Long Distance Communication
}

\author{
Faisal Nadeem \\ M.Tech scholar \\ Dept. of ECE \\ SHIATS, Allahabad
}

\author{
Neelesh Agrawal \\ Asst. Professor \\ Dept. of ECE \\ SHIATS, Allahabad
}

\author{
A.K. Jaiswal \\ Professor and H.O.D \\ Dept. of ECE \\ SHIATS, Allahabad
}

\author{
Navendu Nitin \\ Asst. Professor \\ Dept. of ECE \\ SHIATS, Allahabad
}

\begin{abstract}
Orthogonal Frequency Division Multiplexing (OFDM) is an multicarrier modulation Format that can be easily adopted by different telecommunication standards such as LTE, LTE-A, Wi-Fi \& WiMAX etc, now getting used in optical fiber communication. Chromatic dispersion arises due to Inter Symbol Interference (ISI) and it is serious issue in longdistance communication. The performance of CO-OFDM / WDM-RoF System has been analyzed for long distance communication by measuring the Q-factor and Bit Error Rate (BER).
\end{abstract}

\section{Keywords}

Wavelength Division Multiplexing (WDM), Radio over Fiber (RoF), Coherent-Optical-Orthogonal-Frequency- Division Multiplexing (CO-OFDM), Bit Error Rate (BER), Quality Factor (Q-Factor)

\section{INTRODUCTION}

WDM is a technique of multiplexing more than one optical carrier signals of different wavelength over a single fiber by using different wavelength of laser to carry different signals, and it can achieve a greater capacity, higher data rate and good flexibility at relatively low cost and system can be easily upgraded [1][2]. Rof (Radio Over Fiber) is an integrated system means radio frequency over the fiber that can facilitate to the wireless network, where the Rof system can be increased the channel flexibility and mobility of application system due to larger bandwidth by using optical fiber and at the same time it decreases the cost and power consumption for wireless network [3]. OFDM (Orthogonal frequency division multiplexing) is modulation technique based on an approach as combination of modulation and multipath access for future broadband wireless communication. CO-OFDM system is nothing but a combination of basic 5 components like OFDM Transmitter, RF to Optical (RTO) or Up Converter, Optical Link, Optical to RF (OTR) or Down Converter and OFDM Receiver.

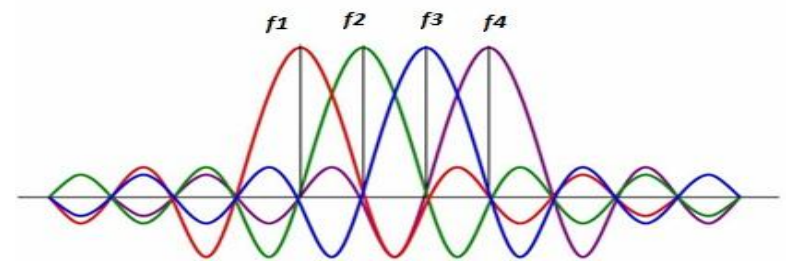

Fig-1 OFDM Spectrum

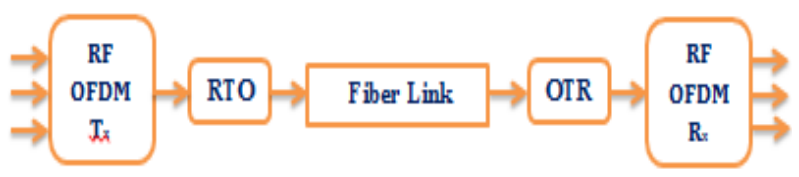

Fig. 2. CO-OFDM communication system

\section{SYSTEM DESCRIPTION}

The system consists of $5 \mathrm{RF}$ signals transmitted over single mode optical fiber at a distance $60 \mathrm{~km}$ and received by 5 remote stations. In transmitter side RF signal is modulated by QAM-OFDM. Li-Nb Mach-Zehnder is used to modulate the OFDM signal into optical carrier. Here, laser is used having frequency of $193.05,193.1,193.15,193.20 \& 193.25 \mathrm{THz}$ as an optical source. QAM modulate the RF signal at the rate of $2 \mathrm{bit} / \mathrm{symbol}$. The QAM signal is then connected to OFDM modulator with 512 subcarriers and 1025 FFT point [4]. The in phase and quadrature signal from OFDM modulator is transmitted to optical modulator. The 5 optical signals from different sources are then multiplexed by $5 \times 1$ WDM to transmit the optical signal over single fiber simultaneously. In channel side two optical gains are used with $60 \mathrm{~km}$ optical fiber having gain of $13 \mathrm{~dB}$. At receiver side 1x5 WDM demultiplexer is used to transmit the signal to 5 different remote stations [5]. At remote station coherent detection is used here for dispersion compensation. Coherent detector consists of local oscillator having wavelength equivalent to laser in transmitter side. Each coherent detector consists of 2 PIN diodes and 2 couplers [6][7]. After detecting the signal the signal is send to OFDM demodulator [8]. The resulting signal is then fed to QAM decoder to convert it in digital signal [9]. BER analyzers are used to analyze the performance of the system.

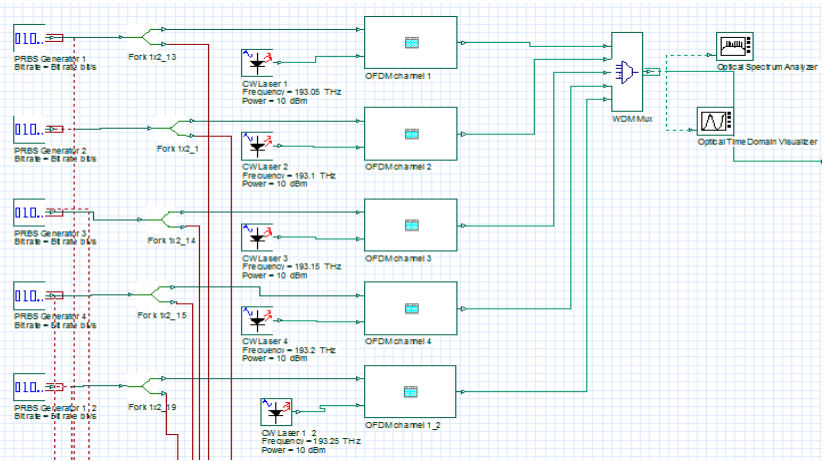

Fig. 2.1. Simulation schematic of CO-OFDM Transmitter 


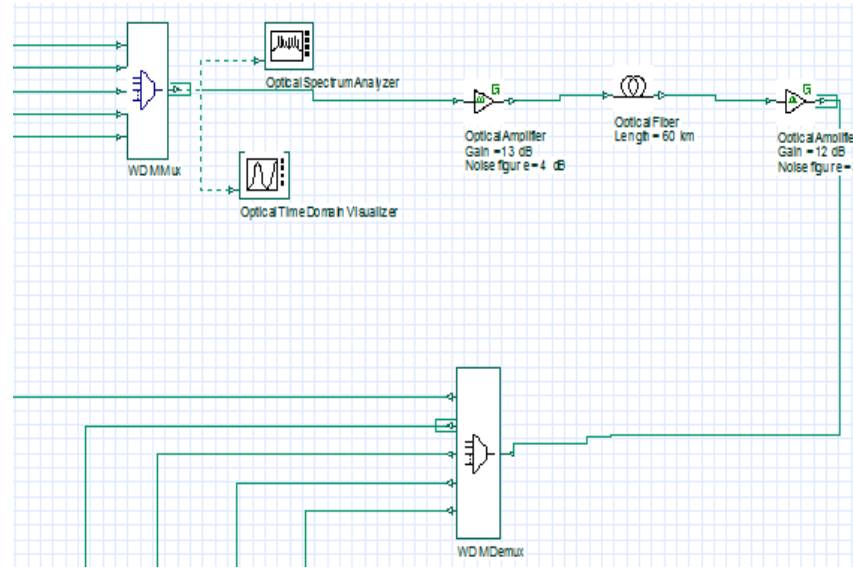

Fig. 2.2. WDM channel

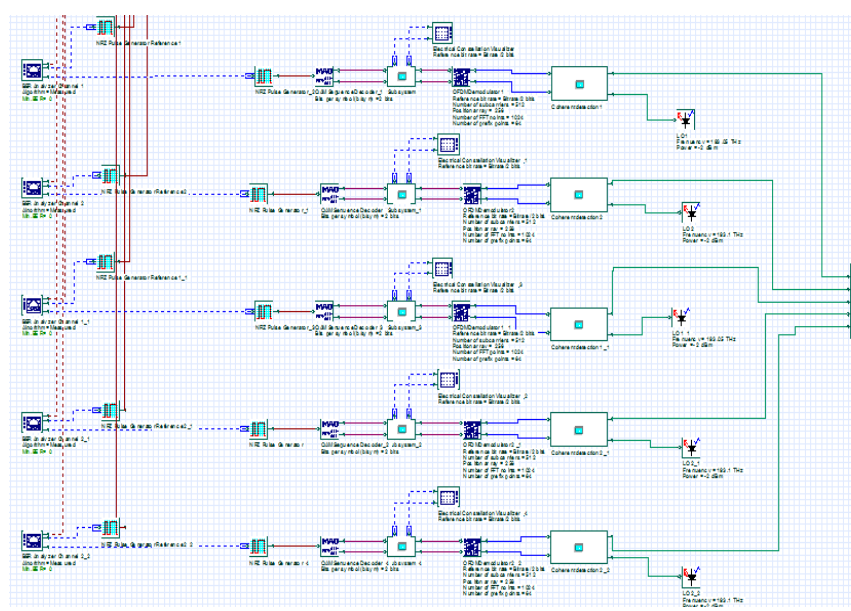

Fig. 2.3. Simulation schematic of CO-OFDM Receiver

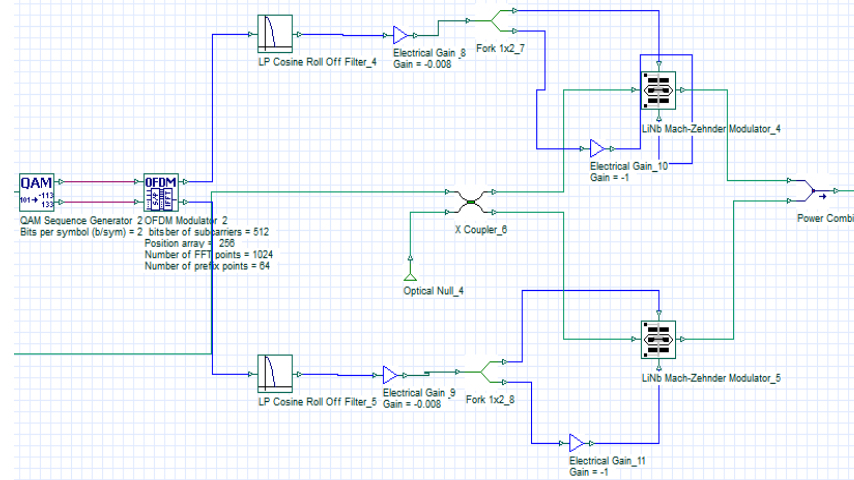

Fig. 2.4. OGDM Channel Subsystem

\section{RESULT AND DISCUSSION}

In this paper two types of analyzer and visualizer are uses like Optical spectrum analyzers and Bit error rate analyzer. Power spectrum analyzer at the Transmitter sides shows that there are five variable signals of frequencies 193.05, 193.1, 193.15, $193.20 \& 193.25 \mathrm{THz}$ having power gain of $-42 \mathrm{dBm}$. These frequencies are transmitted on the fiber link of $60 \mathrm{~km}$. At the receiver side, getting power gain of $-16 \mathrm{dBm}$.

\section{룹 Optical Spectrum Analyzer}

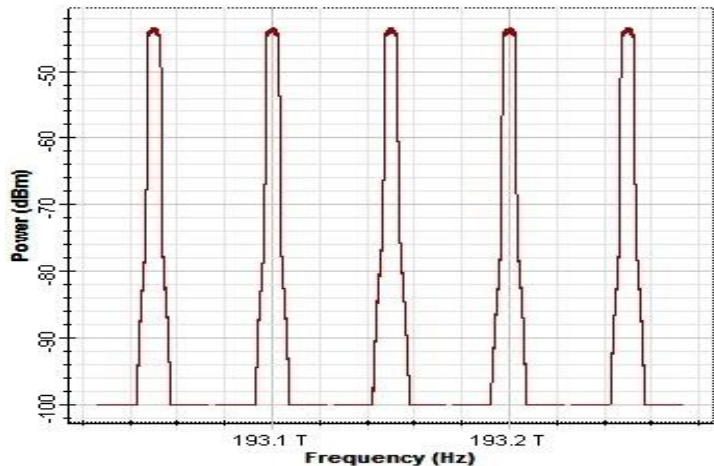

Fig. 3.1. Input optical spectrum of the five signal Frequencies

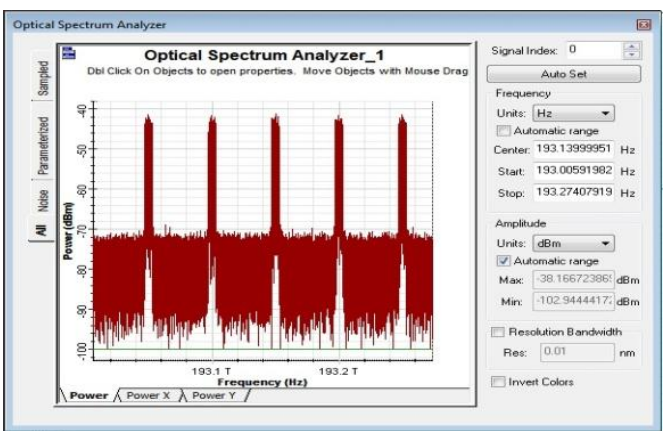

Fig. 3.2. Output optical spectrum of the five signal Frequencies

를

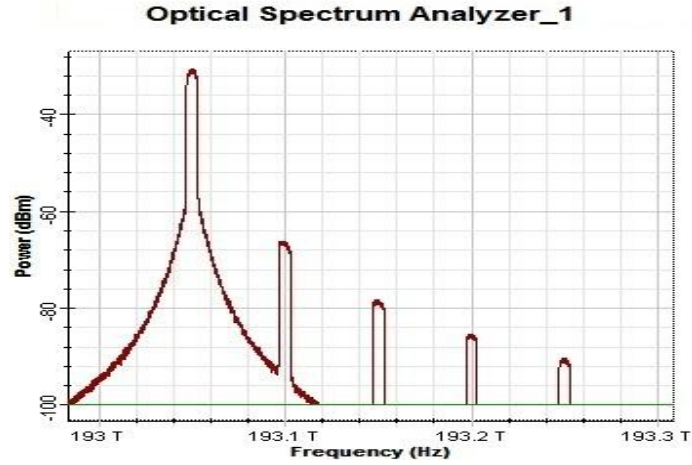

Fig. 3.3 Output of signal frequencies at $193.05 \mathrm{THz}$

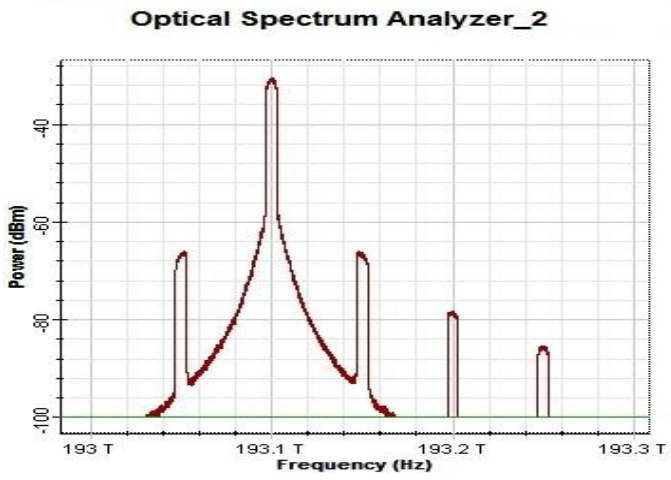

Fig. 3.4 Output of signal frequencies at $193.10 \mathrm{THz}$ 


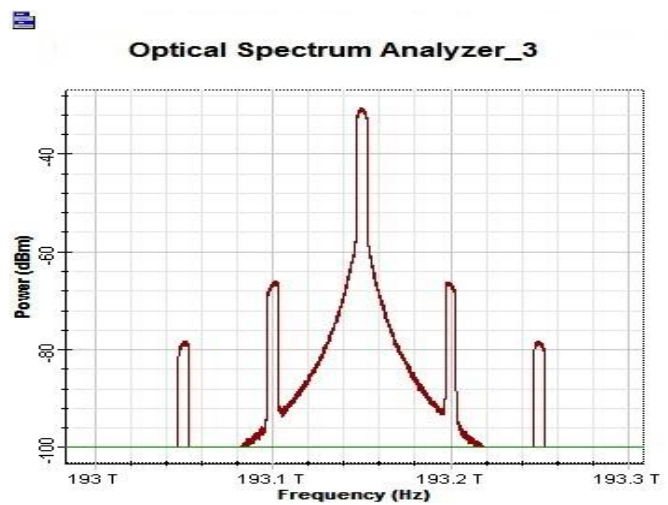

Fig. 3.5 Output of signal frequencies at $193.15 \mathrm{THz}$ 룹

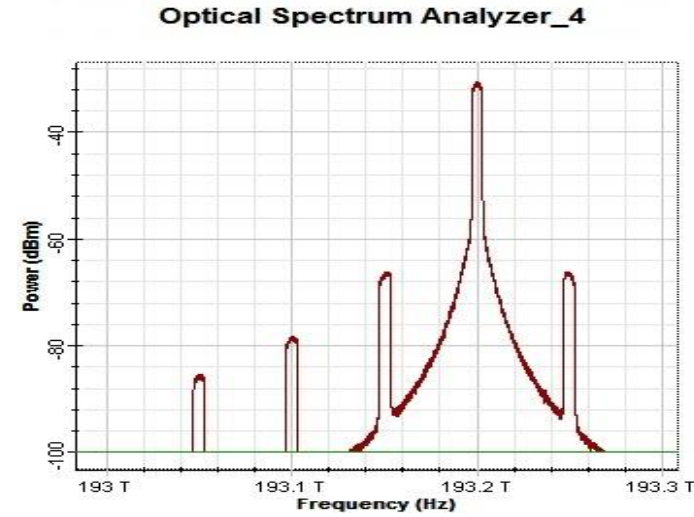

Fig. 3.6 Output of signal frequencies at 193.20THz

룰

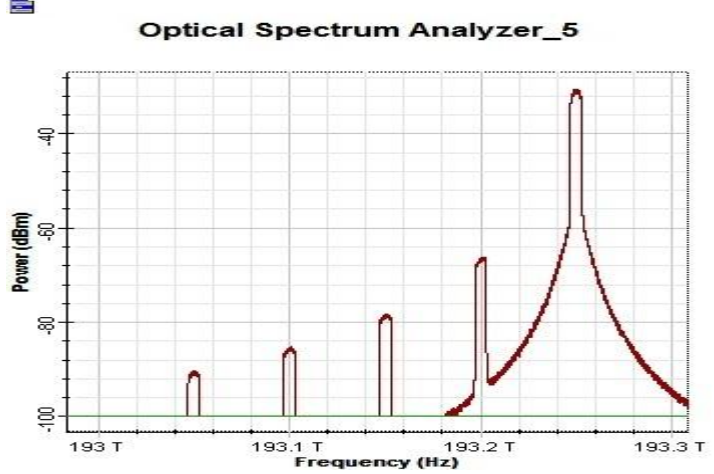

Fig. 3.7 Output of signal frequencies at $193.25 \mathrm{THz}$

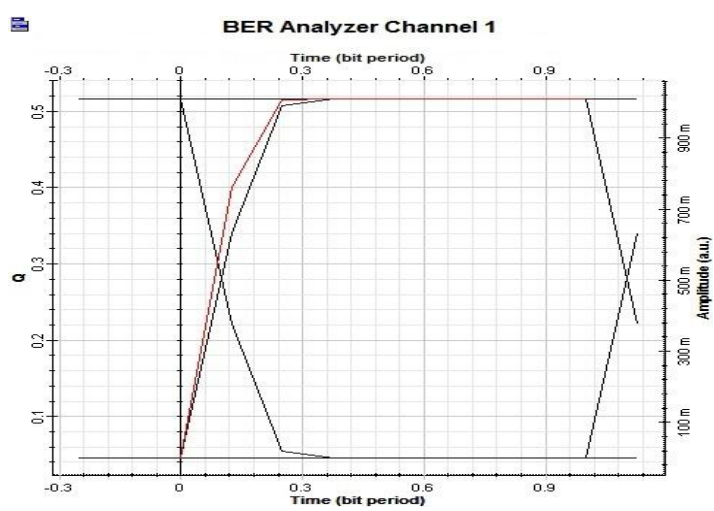

Fig 3.8 Eye diagram of signal Freq 193.05 THz

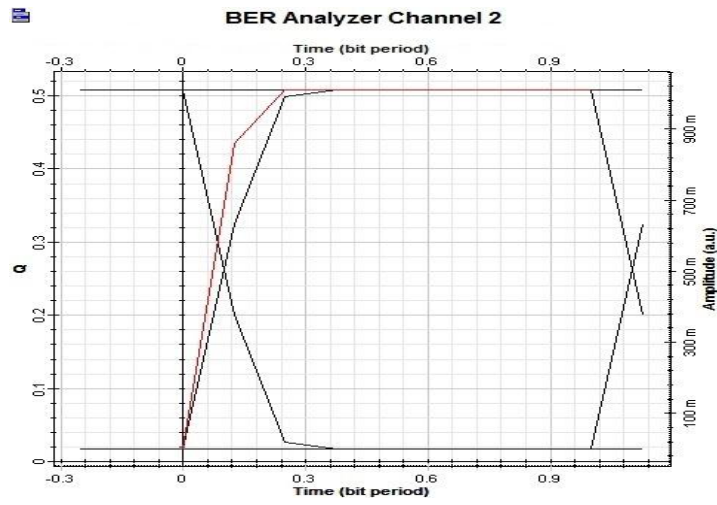

Fig 3.9 Eye diagram of signal Freq $193.10 \mathrm{THz}$

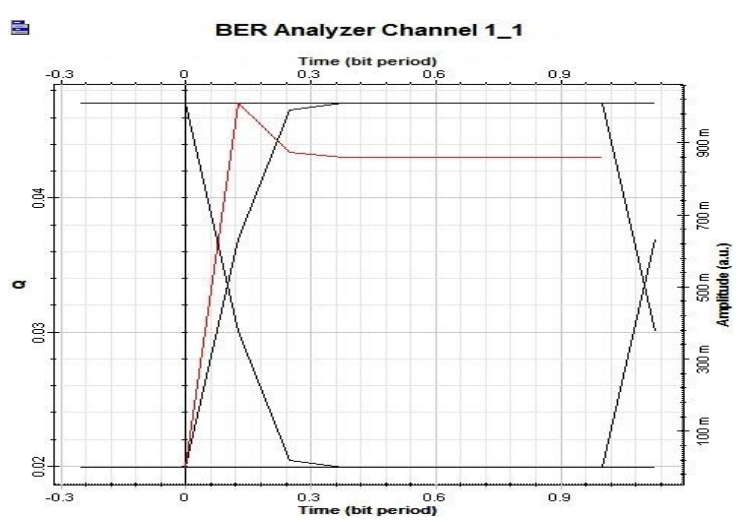

Fig 3.10 Eye diagram of signal Freq $193.15 \mathrm{THz}$

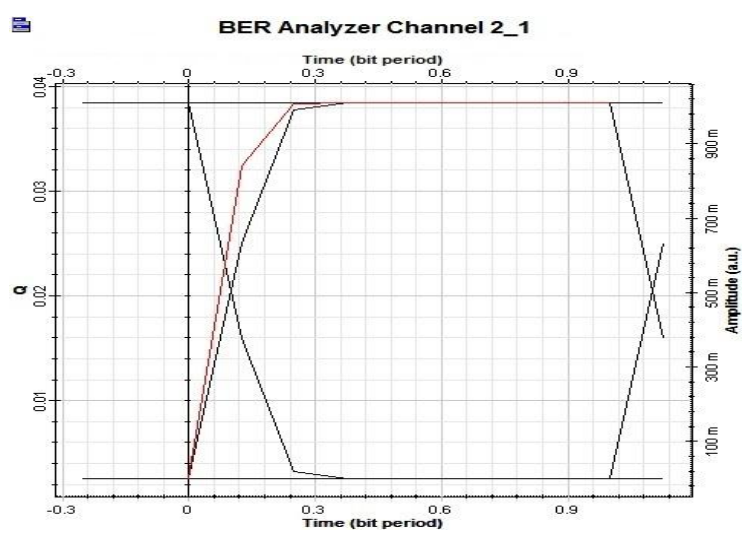

Fig 3.11 Eye diagram of signal Freq 193.05 THz

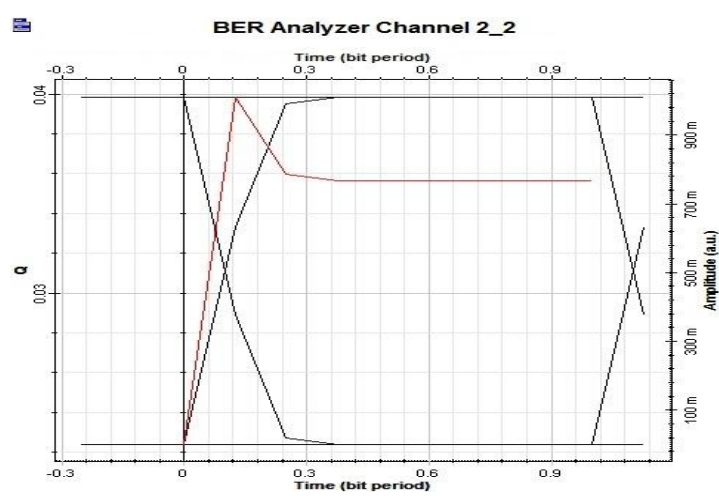

Fig 3.12 Eye diagram of signal Freq 193.25 THz 


\section{CONCLUSION}

In this paper it has been presented that the OFDM-RoF system has achieved RF signal through the optical fiber using Optisystem simulation software. The approach of this work is to compensate higher order dispersion of Coherent detection WDM Optical OFDM system using Phase Modulator and compare the performance of optical spectrum with optical fiber. The result shows the output of RF signal is little degraded as compare to input value but the signal is considerable. From the result it has been observed that the orthogonality of OFDM signal can be easily maintained in 5QAM format at $12 \mathrm{Gbps}$ data bit rate.

In future generation wireless and mobile communication system must be increase with high quality bandwidth service for inaccessible area while the recent network service providers facing the problem of insufficient bandwidth for transmission of voice, data and multimedia service for fixed and mobile users. This demand is to be satisfied for wireless system using Orthogonal Frequency Division Multiplexing (OFDM) with Radio over Fiber (RoF) technique.

\section{ACKNOWLEDGEMENT}

I would like to thank my adviser Asst. Prof. Neelesh agarwal for his support and encouragement. I would also like to thank Prof. \& Head A.K. Jaiswal and Asst. Prof. Navendu Nitin to provide valuable advices. The product of this research paper would not be possible without all of them.

\section{REFERENCES}

[1] Gomes, N. J.; Monteiro, P. P.; Gameiro, A. Next Generation Wireless Communications Using Radio over Fiber; Wiley: West Sussex, 2012.

[2] Agrawal, G.P. Fiber-Optic Communication Systems, $3^{\text {rd }}$ ed.; Wiley: New York, 2002.
[3] Lin, C.T.; Wong, E.Z.; Jiang, W.J.; Shih, P.T.; Chen, J.; Chi, S. 28-Gb/s 16-QAM OFDM Radio-over-Fiber System Within 7-GHz License-Free Band at $60 \mathrm{GHz}$ Employing All-Optical Up-conversion. The Conference on Lasers and Electro-Optics/The International Quantum Electronics Conference, Baltimore, MD, 2009; pp 1-2.

[4] R. Karthikeyan, S. Prakasam Asst. Prof., Dept. of SA, SCSVMV University, Kanchipuram, Tamil Nadu , India.

[5] R. Karthikeyan and Dr. S. Prakasam, "A Survey on Radio over Fiber(RoF) for Wireless Broadband Access Technologies", International Journal of Computer Applications (0975-8887), Volume 65, No. 12, February 2013.

[6] Nee, R.V. and Prasad, R. "OFDM for Wireless Multimedia Communications", UK: Artech House Publishers, 2000.

[7] M.S.Awan, Marzuki, E.Leitgeb, F.Nadeem, M.S.Khan and C.Capsoni-Weather effects impact on the optical pulse propagation in free space, $\|$ IEEE $69^{\text {th }}$, Vehicular technology conference, Barcelona, April 2009.

[8] A.Amphawan, S.Chaudhary and V.W.S.Chan, $-2 \times 2$ Gbps 40Ghz OFDM Ro-FSO transmission with mode divison multiplexing, \| Journal of the European optical society, vol. 9, 2014.

[9] I. I. Kim, B. McArthur, and E. Korevaar, - Comparison of laser beam propagation at $785 \mathrm{~nm}$ and $1550 \mathrm{~nm}$ in fog and haze for optical wireless communications, \| Proc. SPIE, 4214, Boston, MA, USA, 2001 